\title{
Prehospital pathways of occipital stroke patients with mainly visual symptoms
}

\section{Räty, Silja}

2018-01

Räty , S , Silvennoinen , K \& Tatlisumak, T 2018 , ' Prehospital pathways of occipital stroke patients with mainly visual symptoms ' , Acta Neurologica Scandinavica, vol. 137 , no. 1 , pp. 51-58 . https://doi.org/10.1111/ane.12807

http://hdl.handle.net/10138/303646

https://doi.org/10.1111/ane.12807

publishedVersion

Downloaded from Helda, University of Helsinki institutional repository.

This is an electronic reprint of the original article.

This reprint may differ from the original in pagination and typographic detail.

Please cite the original version. 


\section{Prehospital pathways of occipital stroke patients with mainly visual symptoms}

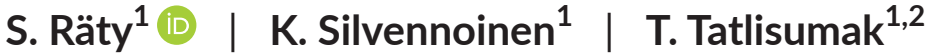

\author{
${ }^{1}$ Department of Neurology, Helsinki University \\ Central Hospital, Helsinki, Finland \\ ${ }^{2}$ Department of Clinical Neurosciences/ \\ Neurology, Institute of Neurosciences and \\ Physiology, Sahlgrenska Academy at the \\ University of Gothenburg and Sahlgrenska \\ University Hospital, Gothenburg, Sweden \\ Correspondence \\ S. Räty, Department of Neurology, Helsinki \\ University Central Hospital, Helsinki, Finland. \\ Email: silja.raty@hus.fi \\ Funding information \\ Suomen Akatemia (Academy of Finland)
}

Objectives: Occipital ischemic strokes typically cause homonymous visual field defects, for which means of rehabilitation are limited. Intravenous thrombolysis is increasingly and successfully used for their acute treatment. However, recognition of strokes presenting with mainly visual field defects is challenging for both patients and healthcare professionals. We studied prehospital pathways of occipital stroke patients with mainly visual symptoms to define obstacles in their early recognition.

Materials \& methods: This observational, retrospective, registry-based study comprises occipital stroke patients with isolated visual symptoms treated at the neurological emergency department of Helsinki University Central Hospital in 2010-2015. We analyzed their prehospital pathways, including time from symptom onset to admission at the neurological emergency department (ODT), the number of points of care, the percentage of patients with ODT $\leq 4.5$ hours, and factors associated with delay.

Results: Among 245 patients, only $20.8 \%$ arrived within 4.5 hours and $6.5 \%$ received IV thrombolysis. Delayed arrival was most often due to patients' late contact to health care. Of the patients, $27.3 \%$ arrived through at least two points of care, and differential diagnostics to ophthalmologic disorders proved particularly challenging. $\mathrm{ODT} \leq 4.5$ hours was associated with EMS utilization, direct arrival, and atrial fibrillation; a visit at an ophthalmologist and initial misdiagnosis were associated with ODT $>4.5$ hours. After multivariable analysis, only direct arrival predicted ODT $\leq 4.5$ hours.

Conclusions: Occipital stroke patients with visual symptoms contact health care late, are inadequately recognized, and present with complex prehospital pathways. Consequently, they are often ineligible for IV thrombolysis. This presents a missed opportunity for preventing permanent visual field defects.

\section{KEYWORDS}

cerebrovascular diseases, emergency care, strokes, thrombolysis, visual field defect

\section{1 | INTRODUCTION}

Posterior cerebral artery strokes constitute approximately $5 \%$ to $10 \%$ of all strokes. ${ }^{1}$ Their most common manifestations are visual

Preliminary results of the study have been previously presented as a poster at International Stroke Conference in Nashville on February 9, 2015. field abnormalities (54\%-93\%), ${ }^{1}$ which often significantly affect daily functions, such as reading, hobbies, or driving a car, and lower a patient's quality of life. ${ }^{2}$ Homonymous visual field defects associated with stroke can recover spontaneously for up to 6 months, and the majority of improvement occurs within a few weeks to 3 months. $^{3-5}$ Unfortunately, the rate of spontaneous recovery is only $18 \%$ to $72 \%{ }^{4-6}$ and no effective rehabilitation method exists, 
which underlines the importance of early recognition and acute therapeutic interventions.

Stroke-related visual symptoms are often challenging to recognize, for both patients and healthcare professionals, although stroke is the most common cause of homonymous hemianopia. ${ }^{3}$ Patients may be unaware of the visual field defects ${ }^{7}$ or confuse them with migraine aura or with ophthalmologic disorders. Posterior circulation (PC) strokes are more frequently misdiagnosed at the emergency department (ED) compared to anterior circulation (AC) strokes, ${ }^{8}$ and IV thrombolysis may be withheld due to patients' lower National Institutes of Health Stroke Scale (NIHSS) score. ${ }^{9}$ Moreover, PC strokes appear to accompany a longer prehospital delay ${ }^{10-12}$ and door-toneedle time ${ }^{11,13}$ compared to $A C$ strokes, despite their equally good clinical outcome when treated with IV thrombolysis. ${ }^{14,15}$ However, the clinical picture of PC stroke is often dominated by other symptoms and signs, and therefore, studies on PC stroke in general may not be representative of occipital stroke. Although occipital stroke has received relatively little attention, these patients also seem to benefit from IV thrombolysis. ${ }^{16}$

This single-center, observational, retrospective, registry-based study aims to identify the prehospital pathways and delays of occipital strokes presenting with mainly visual symptoms, to investigate obstacles in their recognition, and to determine factors associated with greater delays.

\section{2 | MATERIALS \& METHODS}

All ischemic stroke patients (ICD-10 diagnosis code: 163) treated at the Neurological Emergency Department of Helsinki University Central Hospital (HUCH) between 2010 and 2015 were screened from our electronic hospital database. Among them, we searched for patients meeting the following inclusion criteria: (i) occipital ischemic stroke either visible in CT or MRI scan or diagnosed by clinical criteria, (ii) acute visual field symptom compatible with occipital stroke as the leading symptom, (iii) no other prominent neurological focal symptoms, (iv) stroke occurrence out of hospital, and (v) no primary treatment in another neurological unit.

Stroke patients with other neurological deficits, such as hemiparesis or dysphasia, were excluded because these manifestations may overshadow visual symptoms. Other mild accompanying symptoms, such as headache, nausea, dizziness, or mild sensory disturbances, were allowed. In-hospital onset stroke patients and patients primarily treated in other neurological units were excluded due to their incomparable diagnostic pathways. $\mathrm{HUCH}$, the single neurological ED and the only unit providing thrombolysis and thrombectomy in Helsinki and Uusimaa region, was selected as the endpoint of the prehospital pathway. The HUCH neurological ED provides the tertiary emergency and urgent stroke service for the population of Helsinki and Uusimaa region (catchment area of approximately 1.6 million) and treats 5500-7500 neurological patients yearly. According to the local prehospital guidelines, all previously independent patients of over 16 years of age with suspected stroke of onset less than 2 weeks ago are to be referred to the neurological ED for evaluation. Furthermore, patients with suspected stroke of onset $\leq 4.5$ hours should be transported as a priority, and the on-call stroke physician alerted prior to arrival. $^{17}$

The data collected from medical records included demographics, patient history, stroke symptoms, clinical findings, imaging results, symptom-onset time, time of the first contact to health care, the number of healthcare units visited before admission to the neurological ED, admission time, the first suspected diagnosis, and treatment with IV thrombolysis. The delays from symptom onset to neurological ED admission (onset-to-door time, ODT) were analyzed. Symptom onset was defined as the time when either the patient or an observer first noticed stroke symptoms or, in case of wake-up stroke or if the patient was unable to report the onset, based on the last known symptom-free time. Admission time to the ED was the time documented by the triage nurse upon the patient's arrival. ODT was divided into the following categories: $\leq 4.5$ hours, $4.5-24$ hours, 1-7 days, 8-14 days, and >14 days. For some of the cases with symptom onset on the day before admission, the time of onset could not be determined accurately enough to allow for classification into delay less or over 24 hours. In these cases, the delay was defined as less than 24 hours if the patient arrived before 3 pm, or over 24 hours if the patient arrived after $3 \mathrm{pm}$.

We determined the number of patients who arrived within 4.5 hours, the time window for thrombolysis. ${ }^{18}$ To analyze factors associated with early arrival, we compared them to those with ODT >4.5 hours in regard to their demographics, patient history, symptoms or findings, and diagnostic pathways. In addition, we investigated whether there was positive development between the earlier (years 2010-2012) and the later parts (2013-2015) of our study.

Among patients with ODT $\leq 4.5$ hours, we investigated whether they were evaluated according to the thrombolysis protocol, if they received IV thrombolysis, and if not, why. Primary reasons for arrival beyond 4.5 hours were classified into the following categories: patient-dependent delay (first contact to health care after 4 hours from symptom onset), misdiagnosis in health care, inadequate recognition of a thrombolysis candidate in the first point of care, contraindication to thrombolysis, or unclear symptom duration. This study received adequate research permits from the $\mathrm{HUCH}$ (31.5.2013, 88/2013). According to Finnish law, registry-based studies with no patient contact do not require ethical approval.

\section{1 | Statistical analysis}

The comparison of dichotomous variables was performed with chisquare test or Fisher's exact test and continuous variables with MannWhitney $U$-test. Variables with $P<.2$ were included in the multivariable analysis with logistic regression. Statistical significance was set at 0.05 (two sided). Odds ratios and confidence intervals were calculated for variables with statistically significant adjusted $P$-values. Data availability was $>97 \%$ for all variables, and missing data were excluded from the analyses. All statistical analyses were performed with SPSS 22 (IBM, Armonk, NY, USA). 
TABLE 1 Demographics, symptoms, clinical findings, and features of prehospital pathway presented for all patients and according to the delay to the neurological ED

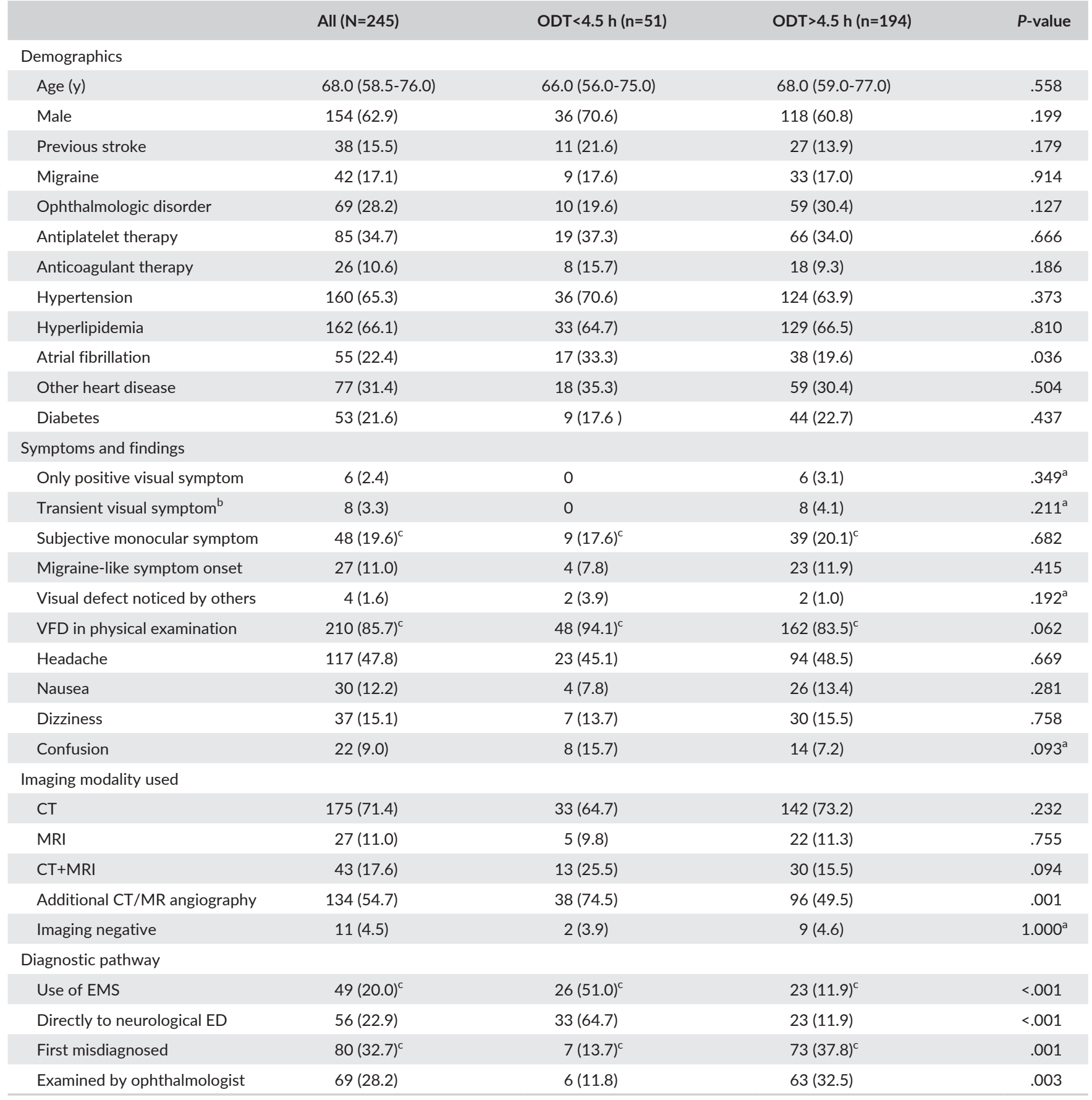

Data are given as median (IQ range) or $\mathrm{n}(\%)$.

ED, emergency department; EMS, emergency medical services; ODT, onset-to-door time; VFD, visual field defect.

${ }^{\text {a}}$ Fisher's exact test.

${ }^{\text {b }}$ Symptom duration less than $24 \mathrm{~h}$.

${ }^{\mathrm{c}}$ Data availability $>99 \%$.

\section{3 | RESULtS}

Among 10775 stroke patients, we found 245 individuals (2.3\%) meeting the inclusion criteria during the study period. Their demographics, medical history, clinical presentation, and diagnostic pathways are presented in Table 1. The imaging-negative patients who were diagnosed based on clinical criteria were scanned with either CT ( $n=9)$ or CT and CTA ( $\mathrm{n}=2)$.

The exact symptom-onset time was reported for $33.5 \%$ and for the rest with the accuracy of hours or days. ODT ranged from 20 minutes to 5 weeks. $29.0 \%$ made their first contact to health care within 4 hours from symptom onset, and $20.8 \%$ arrived at the neurological 


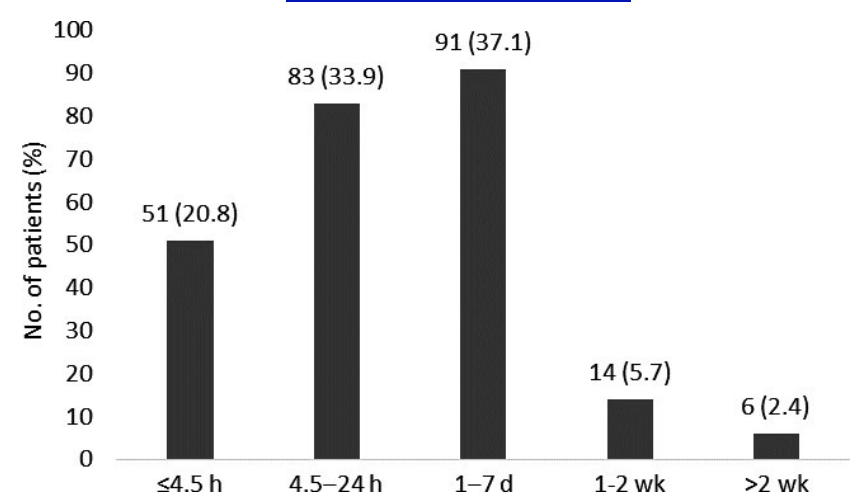

FIGURE 1 Delay from symptom onset to arrival at the neurological ED. ED, emergency department

ED within 4.5 hours, $54.7 \%$ within 24 hours, and $91.8 \%$ within 1 week (Figure 1). Whereas $22.9 \%$ of the patients arrived directly at the neurological ED, the rest first contacted at least one other healthcare unit: $49.0 \%$ visited one, $24.9 \%$ two, and $2.4 \%$ more than two units (Figure 2). Furthermore, 11.4\% were first discharged and $28.2 \%$ were evaluated by an ophthalmologist before the correct diagnosis, two of whom were referred to consultation after being primarily misdiagnosed at the neurological ED. Only $20.0 \%$ were transported to their first point of care by EMS. Points of care before the neurological ED included public primary care, private practice, public hospital's department of ophthalmology, communal hospitals, and non-neurological EDs of the region.

Only $10.2 \%$ of all patients, and $45.1 \%$ of those admitted within 4.5 hours, arrived as candidates for thrombolysis. Of them, two actually arrived outside the time window. On the other hand, a further 10 were recognized after their arrival, and altogether $13.5 \%$ of all patients, and $64.7 \%$ of those arriving within 4.5 hours, were evaluated according to the thrombolysis protocol. Eventually, $6.5 \%$ of all patients and $31.4 \%$ of those arriving within 4.5 hours received IV thrombolysis. None of the patients underwent thrombectomy, either due to ineligibility on account of mild symptoms or contraindication, or lack of proximal thrombosis in angiography. Figure 3 and Table 2 outline the pathways of the patients.

Of the patients who arrived within 4.5 hours, but were not assessed in the expedited thrombolysis candidate pathway, only $17.9 \%(n=5)$ were missed because of incorrect diagnosis of either ophthalmologic disorder $(n=3)$ or migraine $(n=2)$. Other reasons for not evaluating a patient according to the thrombolysis protocol, despite an appropriate time window, included poor recognition by neurological ED personnel $(n=3)$, low NIHSS score $(n=3)$, contraindication $(n=1)$, or the reason was unavailable $(n=6)$. The most common arguments to abstain from IV thrombolysis after proper evaluation were contraindication $(n=9)$ and low NIHSS score $(n=5)$, but two patients were also misdiagnosed.

The primary reason for ODT beyond 4.5 hours was patientdependent delay ( $n=143,73.4 \%$ of patients with ODT $>4.5$ hours). Other explanations included an unclear time window $(n=25)$, misdiagnosis in health care $(n=11)$, poor recognition of a potential thrombolysis candidate $(n=6)$, other reason $(n=3)$, or the reason was unavailable

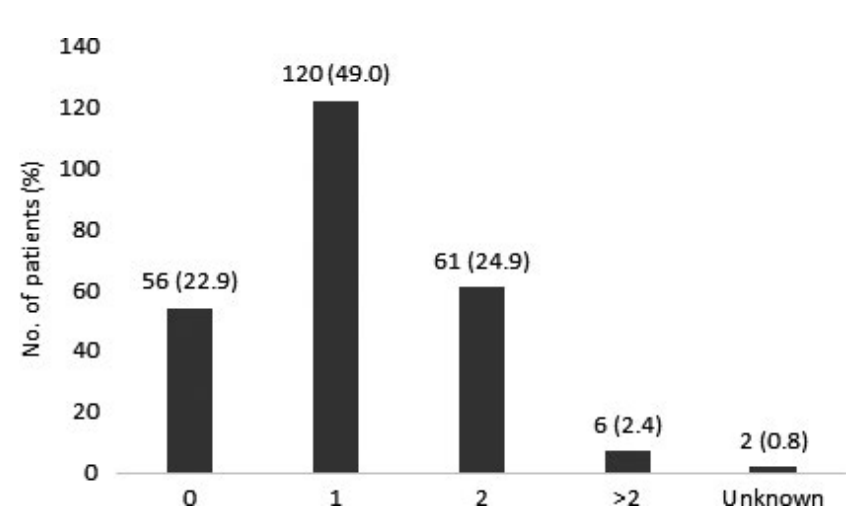

FIGURE 2 Number of points of care before arriving at the neurological ED. ED, emergency department

$(n=6)$. Among patients who contacted health care within 4.5 hours, poor recognition prohibited $38 \%$ from evaluation for thrombolysis.

In $32.7 \%$, either a physician or EMS personnel first suspected other etiology than stroke: most frequently ophthalmologic disorders $(n=54)$ or migraine $(n=11)$. Most misinterpretations occurred by primary care physicians $(n=52)$.

Between the patients with ODT $\leq 4.5$ and $>4.5$ hours, several statistically significant differences arose (Table 1). Shorter ODT was associated with EMS utilization ( $51.0 \%$ vs $11.9 \%, P<.001)$, direct arrival (37.3\% vs $88.7 \%, P<.001$ ), not being examined by an ophthalmologist (32.5\% vs $11.8 \%, P=.003$ ), correct first diagnosis (82.3\% vs $60.8 \%$, $P=.001$ ), and atrial fibrillation (33.3\% vs $19.6 \%, P=.036)$. However, after multivariable analysis, only arriving directly $(P<.0001$, OR 13.31 , $95 \% \mathrm{Cl} 6.47-27.38$ ) remained statistically significant. When we compared the years 2010-2012 and 2013-2015, the number of patients with ODT $\leq 4.5$ hours increased from $15.9 \%$ to $26.1 \%(P=.05)$ and EMS utilization from $14.3 \%$ to $26.1 \%(P=.025)$ (Table 2$)$. The groups did not differ significantly in regard to demographics, patient history, or clinical symptoms and findings.

\section{DISCUSSION}

This study shows that there are significant delays in recognition of occipital stroke presenting predominantly with visual symptoms. Only $20.8 \%$ of the patients arrived at the neurological ED within 4.5 -hour time window of IV thrombolysis, the rate of which was merely $6.5 \%$. The most common reason for the delayed arrival was patients' late contact to health care, but their recognition was also inadequate, with as many as $27.3 \%$ arriving through more than one point of care. Notably, only $20.0 \%$ of the patients used EMS. Factors associated with ODT $\leq 4.5$ hours were arrival by EMS, direct pathway to the neurological ED, and atrial fibrillation, whereas a visit at an ophthalmologist and initial misdiagnosis were associated with ODT $>4.5$ hours. After multivariable analysis, only direct arrival independently predicted ODT $\leq 4.5$ hours.

ODT in our study ranged from 20 minutes to 5 weeks, with only one-fifth of the patients arriving within 4.5 hours. In a review by 


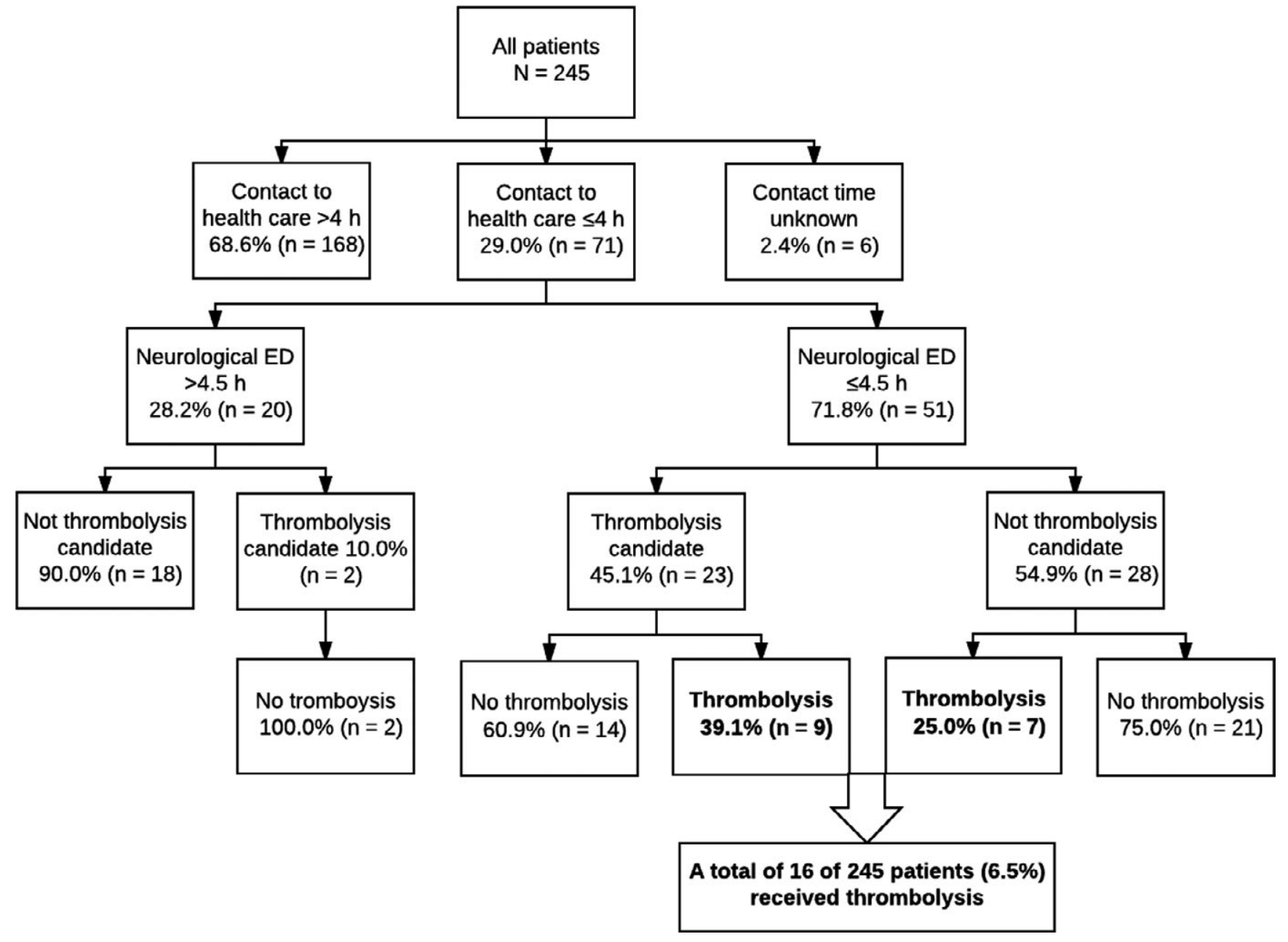

FIGURE 3 Flowchart outlining the pathway of the patients

Evenson et al. comprising 123 studies in 1987-2007, the percentage of acute stroke patients admitted within 3 hours varied between $6 \%$ and $92 \%{ }^{19}$ however, many of the studies used truncated delay times, and the majority were conducted before the establishment of IV thrombolysis. More recent studies have reported percentages of 25\%-60\% (in 3-3.5 hours) for all strokes ${ }^{10,20,21}$ and 53\%-56\% for PC strokes ${ }^{11,12}$-all higher than in our study. The low number of patients with ODT $\leq 4.5$ hours was reflected in the thrombolysis rate that was considerably lower than the $26.9 \%$ previously reported for all ischemic stroke patients treated in the same clinic in 2011-2013, ${ }^{22}$ resembling findings on PC strokes. ${ }^{12}$ This is unfortunate because the majority of occipital stroke patients with isolated homonymous hemianopia treated with IV thrombolysis experience improvement. ${ }^{16}$ Considering the efficacy of early secondary prevention, ${ }^{23}$ it is equally worrisome that almost half of the patients arrived after 24 hours and $8.2 \%$ even after 1 week.

ODT $>4.5$ hours was most often attributed to patients' late contact to health care, suggesting that they do not recognize visual symptoms as a manifestation of stroke. This is in line with a review that found patients' unawareness and lack of urgency to seek medical help as main barriers to IV thrombolysis. ${ }^{24}$ In a recent study, only $5 \%$ of acute stroke patients regarded visual disturbances as a stroke symptom, in contrast to over $30 \%$ for speech difficulties and unilateral weakness. ${ }^{21}$ Moreover, patients with visual symptoms seem to rely on EMS less frequently than those with other neurological defects. ${ }^{25}$ Our results support these observations, with a lower percentage of patients using EMS compared to the $22 \%-65 \%$ reported for all stroke patients. ${ }^{10,11,20,26-31}$

Not only patients, but also healthcare professionals experienced difficulties in recognizing stroke-related visual symptoms, as over a quarter of patients arrived through at least two points of care. Because the prehospital pathway to the neurological ED without misdiagnosis is either directly via EMS or by referral through one healthcare unit, this number coarsely demonstrates the frequency of inadequate recognition in health care. In addition, in some occasions, misdiagnosis lengthened the delay without causing extra visits, raising the total number of incorrect initial diagnoses to $32.7 \%$. This is higher than the $22 \%$ previously reported for all strokes, yet almost equal to the $35 \%$ for PC strokes. ${ }^{8}$ Interestingly, in the same study, vision changes were associated with lower odds for misdiagnosis. ${ }^{8}$ Contrary to our study, however, those patients did not present with isolated visual disturbance, which might explain the differing results. 


\begin{tabular}{|c|c|c|c|c|}
\hline $\begin{array}{l}\text { Diagnostic } \\
\text { pathway }\end{array}$ & All $(N=245)$ & $2010-2012(n=126)$ & $2013-2015(n=119)$ & $P$-value \\
\hline $\begin{array}{l}\text { First health care } \\
\text { unit }<4 \mathrm{~h}\end{array}$ & $71(29.0)^{b}$ & $34(27.0)^{b}$ & $37(31.1)^{\mathrm{b}}$ & .525 \\
\hline $\begin{array}{l}\text { Neurological ED } \\
<4.5 \mathrm{~h}\end{array}$ & $51(20.8)$ & $20(15.9)$ & $31(26.1)$ & .050 \\
\hline $\begin{array}{l}\text { Neurological ED } \\
<24 \mathrm{~h}\end{array}$ & $134(54.7)^{\mathrm{b}}$ & $71(56.3)^{b}$ & $63(52.9)^{\mathrm{b}}$ & .695 \\
\hline Wake-up stroke ${ }^{a}$ & $38(15.5)^{b}$ & $21(16.7)^{b}$ & $17(14.3)^{\mathrm{b}}$ & .717 \\
\hline $\begin{array}{l}\text { Arrival as } \\
\text { thrombolysis } \\
\text { candidate }\end{array}$ & $25(10.2)$ & $9(7.1)$ & $16(13.4)$ & .103 \\
\hline $\begin{array}{l}\text { Evaluated as } \\
\text { thrombolysis } \\
\text { candidate }\end{array}$ & $33(13.5)$ & $13(10.3)$ & $20(16.8)$ & .137 \\
\hline Iv-thrombolysis & $16(6.5)$ & $9(7.1)$ & $7(5.9)$ & .690 \\
\hline $\begin{array}{l}\text { Directly to } \\
\text { neurological ED }\end{array}$ & $56(22.9)$ & 25 (19.8) & $31(26.1)$ & .247 \\
\hline Use of EMS & $49(20.0)^{b}$ & $18(14.3)^{b}$ & $31(26.1)^{b}$ & .025 \\
\hline $\begin{array}{l}\text { Discharged before } \\
\text { diagnosis }\end{array}$ & $28(11.4)$ & $9(7.1)$ & $19(16.0)$ & .030 \\
\hline $\begin{array}{l}\text { First } \\
\text { misdiagnosed }\end{array}$ & $80(32.7)^{b}$ & $42(33.3)^{b}$ & $38(32.0)^{\mathrm{b}}$ & .851 \\
\hline $\begin{array}{l}\text { Examined by } \\
\text { ophthalmologist }\end{array}$ & $69(28.2)$ & $36(28.6)$ & $33(27.7)$ & .884 \\
\hline
\end{tabular}

TABLE 2 Pathway to the neurological ED presented for all patients and according to the stroke year

Data are given as $\mathrm{n}(\%)$.

ED, emergency department; EMS, emergency medical device.

${ }^{\mathrm{a}}$ Only defined for patients that contacted health care within $24 \mathrm{~h}$ of symptom-onset.

${ }^{\mathrm{b}}$ Data availability $>97 \%$.

Differential diagnosis to ophthalmologic disorders proved particularly challenging, with more than one-fifth of the patients erroneously misdiagnosed and more than one-fourth examined by an ophthalmologist before admission to the neurological ED. We observed a trend for patients with previous eye disorders to arrive less frequently within 4.5 hours, which may reflect a tendency to interpret their current symptoms as related to prior disease. Surprisingly, a history of migraine lacked a similar effect. Most migraine patients reported that their visual symptoms differed from usual migraine attacks, which may have encouraged them to seek urgent evaluation. In addition, prolonged auras or other atypical manifestations of migraine often prompt a referral to a neurologist, therefore simplifying the prehospital pathway despite misdiagnosis.

Many patients reported monocular symptoms, which could have misled a physician to suspect an ophthalmologic disorder. However, most of these patients had a binocular visual field defect on examination. Although no particular visual symptom or finding was significantly associated with arrival $\leq 4.5$ hours, it is noteworthy that all patients with either only positive or transient visual symptoms arrived later. Positive visual symptoms are likely to be more challenging to differentiate from migraine aura or epileptic symptoms, whereas transient symptoms might be mistaken for transient ischemic attacks and therefore not be evaluated with as much urgency as patients with ongoing symptoms. However, patients with visual field defects frequently misinterpret or lack awareness of their symptoms ${ }^{7}$ and should not be proclaimed asymptomatic without proper examination. Hence, a careful assessment of visual fields is required not only for those reporting binocular visual field defects, but for all patients with acute visual symptoms.

The factors associated with shorter delays agree with previous studies. EMS utilization ${ }^{10,20,26-29,31}$ and direct pathway ${ }^{20,27,30}$ have consistently emerged as predictors for earlier arrival. In $\mathrm{HUCH}$, patients are predominantly admitted either by referral from another healthcare unit or directly by EMS if recognized as a neurological emergency. Therefore, it is understandable that both the use of EMS and direct pathway were associated with ODT $\leq 4.5$ hours. Past results vary more in regard to atrial fibrillation, with both neutral ${ }^{31,32}$ and positive ${ }^{20,29}$ results. The positive association might be explained by patients' and physicians' awareness of atrial fibrillation as a cerebrovascular risk factor. However, the association disappeared after multivariable analysis and was not consistent in regards to other cardiovascular risk factors, similarly to most previous findings. ${ }^{33}$ One previous study found no association between hemianopia and prehospital delay. ${ }^{32}$

Our results show an increase in the proportion of patients with ODT $\leq 4.5$ hours during the study period, agreeing with previous reports. ${ }^{19}$ We also observed more frequent use of EMS, which is likely to contribute to the greater number of patients eligible for thrombolysis. In addition, the improvement may reflect healthcare professionals' 
increasing knowledge of the efficacy of IV thrombolysis for patients with isolated visual field defects. ${ }^{16}$

The main limitation of the study is its retrospective, registry-based methodology. We received the data only as accurately as recorded in the medical records, so consequently, some of the symptom-onset and contact times to other units were approximated. This was most distinct in the longest prehospital delays. The categorical classification of ODT $\leq 4.5$ hours, however, was executed accurately. The methodology may also underestimate the prevalence of past history of ophthalmologic disorders and migraine, because this is not routinely enquired from stroke patients, although they should belong to the differential diagnostics of visual stroke symptoms. The strength of the study is our large number of patients with uniform neurological presentation of predominantly visual symptoms.

In conclusion, our results suggest that occipital stroke patients with mainly visual symptoms arrive to definitive care late and through many points of care. They do not recognize their symptoms as stroke related, and they contact health care late and are rarely transported by EMS. Moreover, they are frequently misdiagnosed and either referred to, or independently seek the attention of, an ophthalmologist instead of a neurologist.

Prospective studies are required to confirm our findings and the magnitude of the problem. However, these results suggest that to improve these patients' acute treatment, and thereby outcome, awareness of stroke-related visual symptoms should be raised among both the public and healthcare professionals. There is evidence that mass-media campaigns such as FAST (Face, Arm, Speech, Time) have reduced prehospital delay and increased EMS utilization, ${ }^{34,35}$ and also thrombolysis rates. ${ }^{35}$ The effect may mainly be mediated by increased awareness among relatives and bystanders, and not patients themselves, ${ }^{34}$ suggesting campaigns aiming to raise awareness of visual symptoms as a sign of stroke should be targeted at the general public, and not just risk groups. In the UK, the FAST campaign was associated with reduced admissions through general practitioners, ${ }^{34}$ so a similar campaign for visual symptoms could help address the delays associated with primary care visits identified in our study.

\section{ACKNOWLEDGMENTS}

We would like to thank Dr. Heli Silvennoinen for her help in evaluation of MRI and CT scans. This study was funded by a grant from Academy of Finland (Suomen Akatemia, grant no: 263200) through a European Joint Call to Dr. Tatlisumak.

\section{CONFLICTS OF INTEREST}

The authors declare no potential conflict of interests.

\section{REFERENCES}

1. Brandt T, Steinke W, Thie A, Pessin MS, Caplan LR. Posterior cerebral artery territory infarcts: clinical features, infarct topography, causes and outcome. Multicenter results and a review of the literature. Cerebrovasc Dis. 2000;10:170-182.
2. Gall C, Franke GH, Sabel BA. Vision-related quality of life in first stroke patients with homonymous visual field defects. Health Qual Life Outcomes. 2010;8:33.

3. Zhang X, Kedar S, Lynn MJ, Newman NJ, Biousse V. Natural history of homonymous hemianopia. Neurology. 2006;66:901-905.

4. Gray CS, French JM, Bates D, Cartlidge NE, Venables GS, James OF. Recovery of visual fields in acute stroke: homonymous hemianopia associated with adverse prognosis. Age Ageing. 1989;18:419-421.

5. Tiel K, Kolmel H. Patterns of recovery from homonymous hemianopia subsequent to infarction in the distribution of the posterior cerebralartery. J Neuro-Ophthalmol. 1991;11:33-39.

6. Trobe JD, Lorber ML, Schlezinger NS. Isolated homonymous hemianopia. A review of 104 cases. Arch Ophthalmol. 1973;89:377-381.

7. Celesia GG, Brigell MG, Vaphiades MS. Hemianopic anosognosia. Neurology. 1997;49:88-97.

8. Arch AE, Weisman DC, Coca S, Nystrom KV. Wira CR3, Schindler $\mathrm{JL}$. Missed ischemic stroke diagnosis in the emergency department by emergency medicine and neurology services. Stroke. 2016;47:668-673.

9. Sato S, Toyoda K, Uehara T, et al. Baseline NIH Stroke Scale Score predicting outcome in anterior and posterior circulation strokes. Neurology. 2008;70:2371-2377.

10. Agyeman $\mathrm{O}$, Nedeltchev $\mathrm{K}$, Arnold $\mathrm{M}$, et al. Time to admission in acute ischemic stroke and transient ischemic attack. Stroke. 2006;37:963-966.

11. Sommer P, Seyfang L, Posekany A, et al. Prehospital and intra-hospital time delays in posterior circulation stroke: results from the Austrian Stroke Unit Registry. J Neurol. 2017;264:131-138.

12. Sand KM, Naess H, Nilsen RM, Thomassen L, Hoff JM. Less thrombolysis in posterior circulation infarction-a necessary evil? Acta Neurol Scand. 2017;135:546-552.

13. Sarraj A, Medrek S, Albright $\mathrm{K}$, et al. Posterior circulation stroke is associated with prolonged door-to-needle time. Int J Stroke. 2015;10:672-678.

14. Förster A, Gass A, Kern R, Griebe M, Hennerici MG, Szabo K. Thrombolysis in posterior circulation stroke: stroke subtypes and patterns, complications and outcome. Cerebrovasc Dis. 2011;32:349-353.

15. Breuer L, Huttner HB, Jentsch K, et al. Intravenous thrombolysis in posterior cerebral artery infarctions. Cerebrovasc Dis. 2011;31:448-454.

16. Strbian D, Ahmed N, Wahlgren N, Kaste M, Tatlisumak T. SITS Investigators. Intravenous thrombolysis in ischemic stroke patients with isolated homonymous hemianopia: analysis of Safe Implementation of Thrombolysis in Stroke-International Stroke Thrombolysis Register (SITS-ISTR). Stroke. 2012;43:2695-2698.

17. Meretoja A, Strbian D, Mustanoja S, Tatlisumak T, Lindsberg PJ, Kaste M. Reducing in-hospital delay to 20 minutes in stroke thrombolysis. Neurology. 2012;79:306-313.

18. Lees KR, Bluhmki $E$, von Kummer R, et al. Time to treatment with intravenous alteplase and outcome in stroke: an updated pooled analysis of ECASS, ATLANTIS, NINDS, and EPITHET trials. Lancet. 2010;375:1695-1703.

19. Evenson KR, Foraker RE, Morris DL, Rosamond WD. A comprehensive review of prehospital and in-hospital delay times in acute stroke care. Int J Stroke. 2009;4:187-199.

20. Jin $\mathrm{H}$, Zhu S, Wei JW, et al. Factors associated with prehospital delays in the presentation of acute stroke in urban China. Stroke. 2012;43:362-370.

21. Mellon L, Doyle F, Williams D, Brewer L, Hall P, Hickey A. Patient behaviour at the time of stroke onset: a cross-sectional survey of patient response to stroke symptoms. Emerg Med J. 2016;33:396-402.

22. Hubert GJ, Meretoja A, Audebert HJ, et al. Stroke thrombolysis in a centralized and a decentralized system (Helsinki and Telemedical Project for Integrative Stroke Care Network). Stroke. 2016;47:2999-3004

23. Rothwell PM, Giles MF, Chandratheva A, et al. Effect of urgent treatment of transient ischaemic attack and minor stroke on early 
recurrent stroke (EXPRESS study): a prospective population-based sequential comparison. Lancet. 2007;370:1432-1442.

24. Kwan J, Hand P, Sandercock P. A systematic review of barriers to delivery of thrombolysis for acute stroke. Age Ageing. 2004;33:116-121.

25. Kleindorfer D, Lindsell CJ, Moomaw CJ, et al. Which stroke symptoms prompt a 911 call? A population-based study. Am J Emerg Med. 2010;28:607-612.

26. Menon SC, Pandey DK, Morgenstern LB. Critical factors determining access to acute stroke care. Neurology. 1998;51:427-432.

27. Wester P, Radberg J, Lundgren B, Peltonen M. Factors associated with delayed admission to hospital and in-hospital delays in acute stroke and TIA: a prospective, multicenter study. Seek- Medical-Attentionin-Time Study group. Stroke. 1999;30:40-48.

28. Morris DL, Rosamond W, Madden K, Schultz C, Hamilton S. Prehospital and emergency department delays after acute stroke: the Genentech Stroke Presentation Survey. Stroke. 2000;31:2585-2590.

29. Lacy CR, Suh DC, Bueno M, Kostis JB. Delay in presentation and evaluation for acute stroke: stroke time registry for outcomes knowledge and epidemiology (S.T.R.O.K.E.). Stroke. 2001;32:63-69.

30. Chang K, Tseng M, Tan T. Prehospital delay after acute stroke in Kaohsiung, Taiwan. Stroke. 2004;35:700-704.

31. Maestroni A, Mandelli C, Manganaro D, et al. Factors influencing delay in presentation for acute stroke in an emergency department in Milan, Italy. Emerg Med J. 2008;25:340-345.
32. Jorgensen HS, Nakayama H, Reith J, Raaschou HO, Olsen TS. Factors delaying hospital admission in acute stroke: the Copenhagen Stroke Study. Neurology. 1996;47:383-387.

33. Teuschl Y, Brainin M. Stroke education: discrepancies among factors influencing prehospital delay and stroke knowledge. Int J Stroke. 2010;5:187-208.

34. Wolters FJ, Paul NLM, Li L, Rothwell PM. Oxford Vascular Study. Sustained impact of UK FAST-test public education on response to stroke: a population-based time-series study. Int J Stroke. 2015;10:1108-1114.

35. Advani R, Naess H, Kurz M. Mass media intervention in Western Norway aimed at improving public recognition of stroke, emergency response, and acute treatment. J Stroke Cerebrovasc Dis. 2016;25:1467-1472.

How to cite this article: Räty S, Silvennoinen K, Tatlisumak T. Prehospital pathways of occipital stroke patients with mainly visual symptoms. Acta Neurol Scand. 2018;137:51-58. https:// doi.org/10.1111/ane.12807 